\title{
Epidemiology of Vitiligo among Libyan Adult Patients
}

\author{
Aisha BA Eltrabulsi¹, Azza SH Griew², Ali M Gargoom¹, Ghada A \\ Taeib¹, Hala Triki³ ${ }^{3}$ Gamal A Duweb ${ }^{1 *}$ \\ ${ }^{1}$ Dermatology department, Benghazi University, Libya \\ ${ }^{2}$ Family \& Community Medicine Department-Faculty of Medicine, Benghazi \\ University, Libya \\ ${ }^{3}$ Dermatology department, Althawra teachibg hospital, Albeida-Libya
}

\section{Research article \\ Volume 4 Issue 1}

Received Date: February 19, 2019

Published Date: March 20, 2019

DOI: $10.23880 /$ cdoaj- 16000175

*Corresponding author: Dr. Gamal Ahmed Duweb, M.D, Professor of dermatology, faculty of medicine, Benghazi university, Benghazi- Libya, Tel: 00218913752571; Email: drduweb@gmail.com

\section{Abstract}

Background: Vitiligo is a common disease with autoimmune etiology. The chronic nature of disease, long term treatment, lack of uniform effective therapy and unpredictable course of disease is usually very demoralizing for patients suffering from vitiligo.

Aim of the study: To review the demographic data among Libyan vitiligo patients.

Patients and methods: 150 patients above the age of 16 years attended vitiligo clinic in Al Jamhoria hospital; Benghazi Libya during the period of one year were exposed to detailed disease history and thorough dermatological examination.

Results: Our study showed that slightly higher proportion of vitiligo in females (61.3\%) as compared to males (38.7\%). The mean age for patients was 34year and mean duration was 10 years. Positive family history elicited in (26\%) of patients and stress was the commonest aggravating factor which represent (84\%). Clinically, vitiligo vulgaris represent the commonest morphological pattern(35\%), nearly half of patients (48\%) had the disease in both exposed and unexposed sites, $39 \%$ had the disease on exposed site and only $13 \%$ had the disease on unexposed sites. Two third of patients (65\%) had severe lesions (more than 10). Majority of patients (89\%) had no associated disease. About $10 \%$ had either diabetes or hypothyroidism or both.

Conclusion: This study showed that vitiligo constitute a major health problem, it has more female predominance, Stress is the most common etiological factor and exposed body sites are frequently involved.

Keywords: Vitiligo; Autoimmunity; Epidemiology; Libya

\section{Introduction}

Vitiligo is an important, common, chronic, acquired autoimmune amelanocytic skin and/or mucus membrane disorder, characterized by well circumscribed, ivory or chalky white macules or patches $[1,2]$. 


\section{Clinical Dermatology Open Access Journal}

Vitiligo occurs worldwide with an overall prevalence of $1 \%$. However, its incidence varies from 0.1 to $>8.8 \%$ [3] in different countries of the globe.. The highest incidence of the condition has been recorded in Indians from the Indian subcontinent, followed by Mexico and Japan [4]. Vitiligo may occur at any age, from shortly after birth till adulthood, However majority of the vitiligo cases reported begin during the period of active growth. Almost half of the patients present before the age of 20 years and nearly $70-80 \%$ before the age of 30 years $[4,5]$.

All races are affected and both sexes are afflicted [6]. Although the prevalence has also been consistently reported to be higher not always significantly among females than males [7]. Vitiligo susceptibility is not believed to be sex- linked but $6-38 \%$ of patients have family members with the disease indicating a hereditary factor [8].

It is difficult to precisely define the triggering factors for vitiligo Nevertheless, it is essential to elicit the details of history of emotional stress, drug intake, pregnancy, infections, trauma / injury (Koebner's phenomenon) existence prior to the development of vitiligo lesions attempts to bring into focus the various probable triggering factors in the natural history /development of vitiligo $[3,9]$.

It is important to recapitulate associations of vitiligo as they commonly provide circumstantial evidence to its possible etiopathogenesis. Premature graying of the hair, leukotrichia, halo nevus, lichen planus, koebner`s phenomenon and alopecia .areata are frequently reported associations $[10,11]$.

Vitiligo reflects a systemic process that has important implications beyond the skin [12]. In 2005 a survey was conducted on more than 2600 Caucasian vitiligo patients and their close relatives revealed that there is a significantly increased frequencies of autoimmune thyroid disease, pernicious anemia, Addison's disease, and systemic lupus erythematosus [8]. Overall, about $30 \%$ of patients with generalized vitiligo are affected with at least one additional autoimmune/auto inflammatory disorder.

The treatment of vitiligo is unsatisfactory in spite of the repigmentation is the most important goal. In most cases reassurance about nature of the disease and use of effective cosmetic camouflage, treatment with topical steroids, topical immunomodulators, topical \& oral PUVA, Narrow-band UVB phototherapy has been found to be effective and safe for vitiligo $[13,14]$.

\section{Aim of the Study}

To describe the clinical and epidemiological profile of Libyan vitiligo patients.

\section{Materials and Methods}

One hundred and fifty patients attending vitiligo clinic, Al-Jamhoria hospital, Benghazi- Libya over one year period ( January 2015 to January 2016 ) were included in this study. All the patients were exposed to detailed disease history demographic data(age, sex, social status and work status), disease-related characteristics (duration, disease extension, visibility of the lesion, history of an affected family member, , details of current or past treatment and complete dermatological examination. All the patients were above the age of 16 . The data was recorded in the prepared proforma.

All statistical analyses were carried out using the statistical package for the social sciences (SPSS 11.5 for windows). A descriptive analyses was carried out to assess the characteristics of the samples.

\section{Results}

Among 150 patients included in this study 58 patients $(38.7 \%)$ were males and 92 patients (61.3\%) were females. The patient age ranged from 16 year to 75 year (Mean: 34 yr \pm 13.6 ). Concerning the educational level, majority of patients $(65.4 \%)$ were econdary school level or above (Figure 1). More than one third of patients (33\%) were house wives, $24 \%$ were students, $16 \%$ were professionals and minority (4\%) were unemployed as shown in (Figure 2). The mean duration of the illness was (10 years \pm 9.4 ) and ranged from 0.1 to 50 year. Out of 150 patients $(26 \%)$ of patients had positive family history of the disease (Table 1). In our study we found that stress was the most common aggravating factor (84\%) among patients (Figure 3). Regarding morphological patterns of the disease, ( $35 \%$ ) had vitiligo vulgaris which represent the commonest morphological type among the patients, other patterns were seen as acrofacial (17\%), focal (14\%), universalis and generalized (13\%), only (5\%), (3\%) of cases had mucosal and segmental types respectively (Figure 4). Regarding site of exposure, nearly half of patients $(48 \%)$ had the disease in both exposed and unexposed sites, about $39 \%$ had disease on exposed site and $13 \%$ had disease on unexposed site (Figure 5). Severity of the disease was determined by number of vitiligo lesions; quarter of patients had mild lesions (1-4), $10 \%$ had moderate lesions (5-10), and nearly two third (65\%) had severe lesions (more than 10 (Table 2). 
Majority of patients (86\%) had no associated disease with vitiligo, $10 \%$ had either diabetes/hypothyroidism or both and equal proportion $(2 \%)$ of patients had either anemia or diabetes \& hyperthyroidism. Less than one third (31\%) of cases were satisfied with their treatment.

\begin{tabular}{|c|c|c|}
\hline Family history of the vitiligo & No. & \% \\
\hline Positive & 37 & 26 \\
\hline Negative & 74 & 74 \\
\hline Total & 150 & 100 \\
\hline
\end{tabular}

Table 1: Family history of the vitiligo.

\begin{tabular}{|c|c|c|}
\hline Severity & No. & \% \\
\hline Mild (1-4) & 37 & 26 \\
\hline Moderate (5-10) & 15 & 10 \\
\hline Severe (more than 10) & 98 & 64 \\
\hline Total & 150 & 100 \\
\hline
\end{tabular}

Table 2: Severity of the vitiligo.

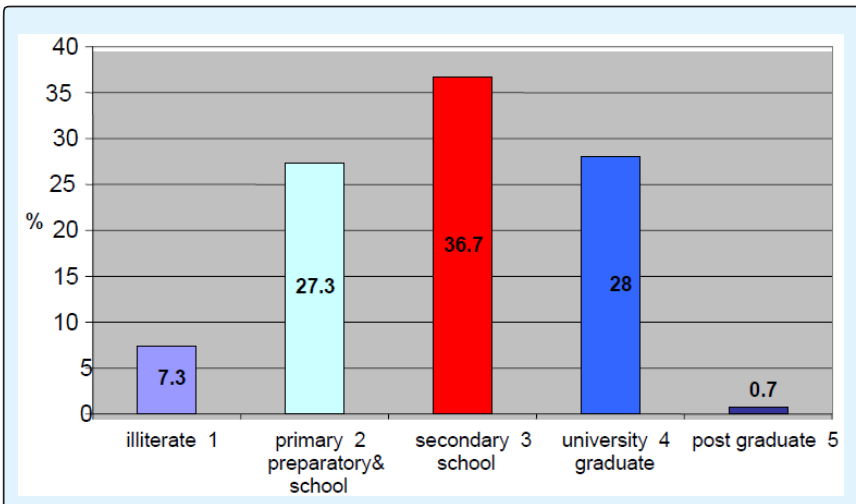

Figure 1: Level of Education of vitiligo cases.

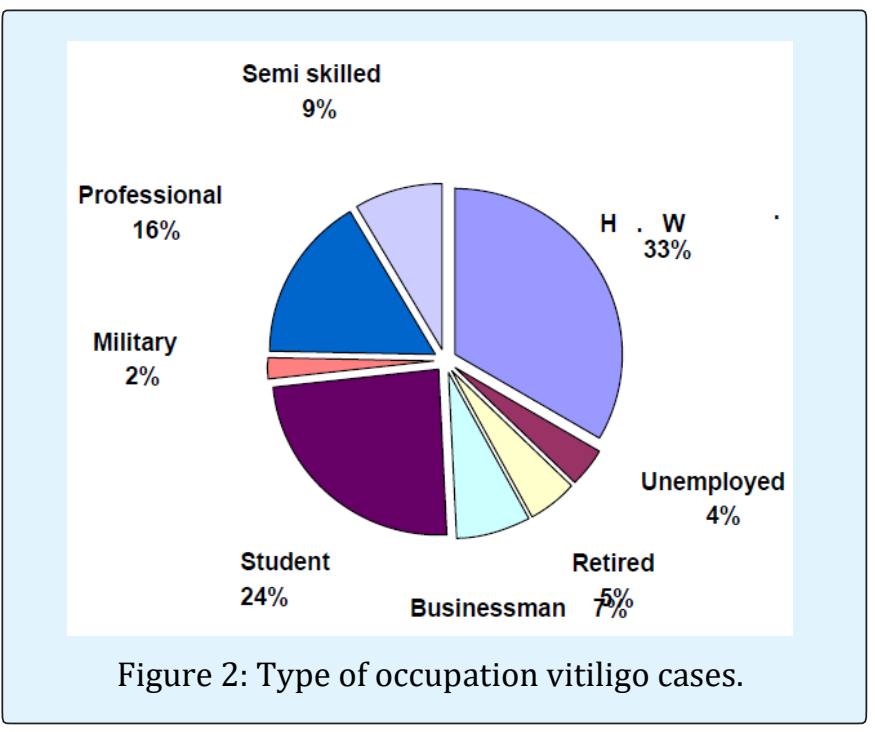

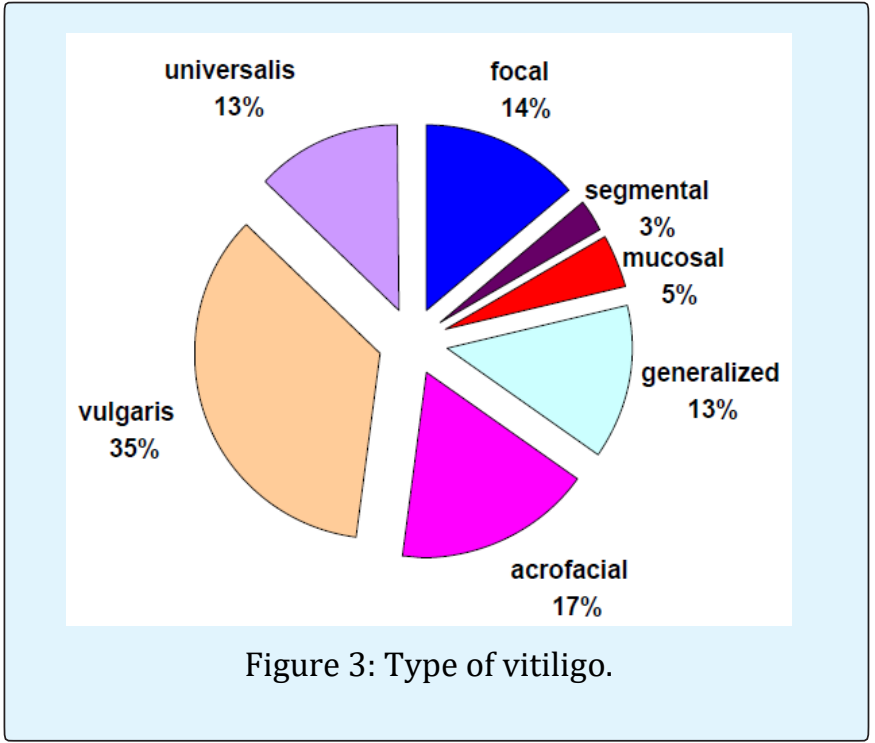
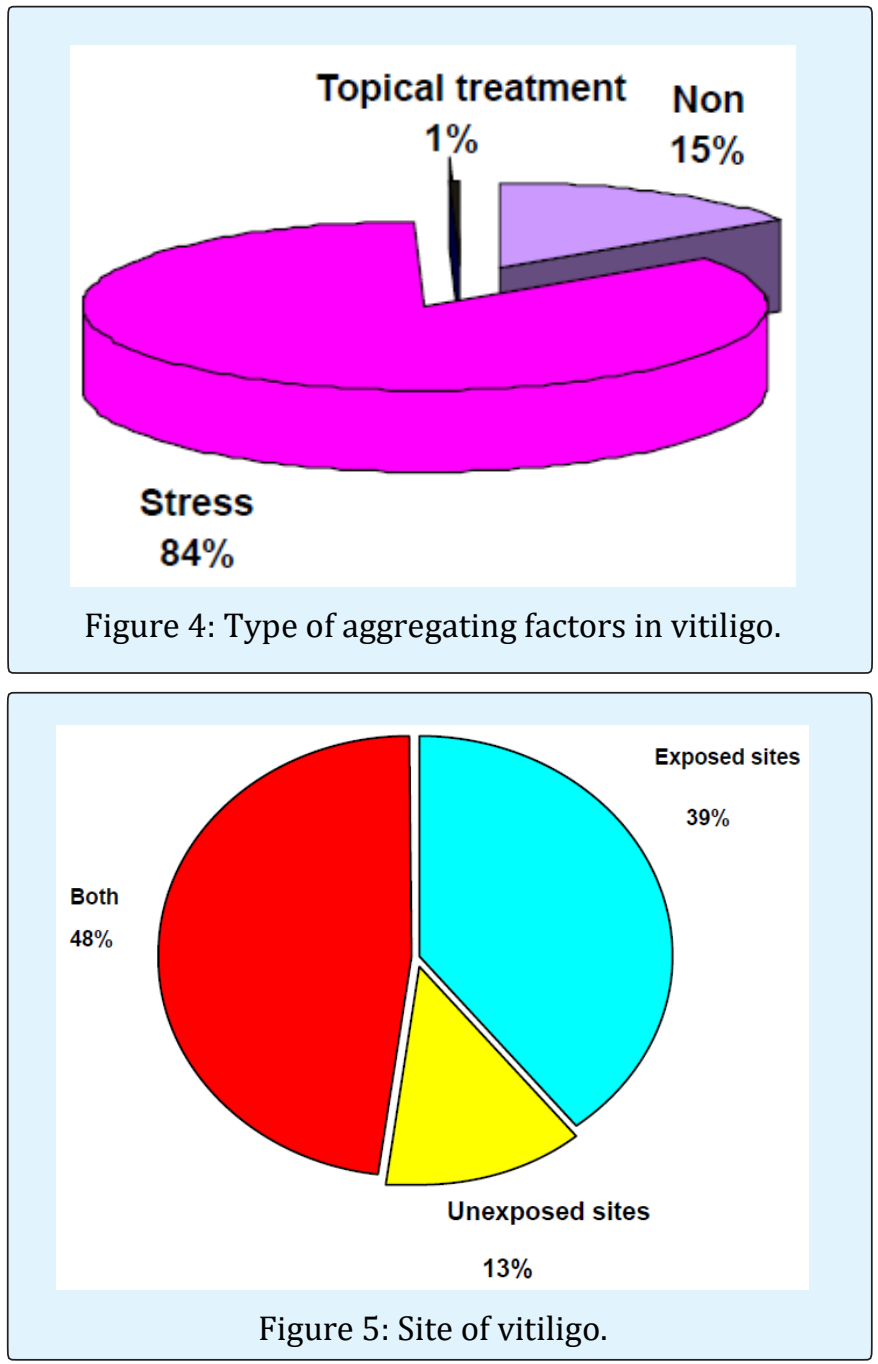


\section{Clinical Dermatology Open Access Journal}

\section{Discussion}

Vitiligo is an acquired depigmentation disorder of great concern affecting 1-4\% of the world population [1]. Vitiligo is disfiguring in all races but particularly more so in dark skinned people because of strong contrast [15]. Vitiligo may develop at any age; onset had been reported from birth to 81 years. However, the peak age of onset was between 10 and 30 years; in $50 \%$ of cases, the age of onset fell within the first two decades of life [16]. The mean age of our studied patients was 34 years; this is in agreement with previous study [17], while in other study [18] the mean age was 45 years.

Both sexes are likely to be affected equally; the female prevalence in some studies can be probably attributed to greater concern about cosmetic defect. On comparing our clinical observations with previous reports we found a slightly higher proportion of vitiligo among females $62 \%$ compared to males $38 \%$, and this show similarity to study carried by L. Borimnejad [19]. A slightly higher proportion among females may not be the true situation and could be due to early reporting of young females as a result of the social stigma in the community.

Majority of patients (65.4\%) were at the secondary school level \& above. One third of our studied patients were housewives. Regarding duration of the disease, in our study it ranged from one month to 50 years while in previous study it ranged from 1 month to 35 years [20].

Positive family history of vitiligo has variously been reported from $5 \%$ to $40 \%$ in different studies. In our study it was $26 \%$, this was dependent only on history taken from the patient or parents $[18,21]$. The precipitating factors were noticed in our study in $85 \%$ of patients, and stress being the most common factor $84 \%$, as reported in previous study where trauma were reported in $13 \%$ and being most common factor [22].

From history taken from patients or their relatives our study revealed association between vitiligo and other diseases such as diabetes mellitus in $4.7 \%$ of vitiligo patients, Gopal et al found diabetes mellitus in $16 \%$ of their vitiligo patients [23]. Regarding type of vitiligo, vitiligo vulgaris was most frequently noticed in our study which is in agreement with studies reported earlier by J Martis, et al. Acrofacial vitiligo observed in $17 \%$ and minority of patients $3 \%$ with segmental vitiligo [21]. In our study the exposed such as face, hand, feet together especially often affected (49\%), followed by face alone $(14 \%)$, feet $(11 \%)$, hand $(7 \%)$, as compared to study done by Dave Shriya which revealed that limbs $77.9 \%$ was the most commonly affected, mucosa (59\%), and the face was involved in $24.1 \%$ of patients 18 .

\section{Conclusions}

Epidemiological analysis of our patients showed that more female were affected by the disease than males, and the mean patient age was 34 years. The mean duration of the disease was 10 years, family history was recorded in $26 \%$ of cases and stress was the most common precipitating factor of the disease. Vitiligo vulgaris represent the commonest morphological form, $65 \%$ had more than 10 lesions and in $87 \%$ of them the exposed sites were involved.

\section{References}

1. Sehgal VN (2004) Vitiligo. Textbook of clinical Dermatology. $4^{\text {th }}$ (Edn.) Jaypee: New Delhi, pp: 99101.

2. Behl PN, Bhatia RK (1971) 400 case of vitiligo - A clinico therapeutic analysis. Ind J Dermatol 17(2): 514.

3. Behl PN, Aggarwal A, Srivastava G (2003) Vitiligo. In: Behl PN, Srivastava G (Eds.), Practice of Dermatology. $9^{\text {th }}$ (Edn.) CBS Publishers: New Delhi, pp: 238-241.

4. Srivastava G (1978) Vitiligo- Introduction Asian Clinic. Dermatol 1: 1-5.

5. Nair BK (1978) Vitiligo-a retrospect. Int J Dermatol 17(9): 755-757.

6. Le Poole C, Boissy RE (1997) Vitiligo. Semin Cutan Med Surg 16:3-14.

7. Hann SK, Lee HJ (1996) Segmental vitiligo clinical findings in 208 patients. J Am Acad Dermatol 35(5): 671-674.

8. Alkhateeb A, Fain PR, Thody A, Bennett DC, Spritz RA (2003) Epidemiology of vitiligo and associated autoimmune diseases in caucasian probands and their families. Pigment Cell Res 16(3): 208-214.

9. Shwartz RA, Janniger CK (1997) Vitiligo. Cutis 60(5): 239-244.

10. Ortonne JP (1989) Psoralen therapy in vitiligo. Clin Dermatol 7(2): 120-135. 


\section{Clinical Dermatology Open Access Journal}

11. Orecchia G, Perfett L (1992) Phototherapy with topical khellin and sunlight in vitiligo. Dermatol 184(2): 120-123.

12. Huggins RH, Janusz CA, Schwartz RA (2006) Vitiligo: A sign of systemic disease. Ind J Dermatol Venereol Leprol 72(1): 68-71.

13. Ortonne JP, Bahadoran P, Mosher DB (2003) Hypomelanoses and Hypermelanoses. In: Freedberg IM, Eisen AZ, Wolff $\mathrm{K}$ (Eds.), Fitzpatrick's Dermatology in General Medicine. 6 ${ }^{\text {th }}$ (Edn.), New York: McGraw Hill, pp: 839-847.

14. Crimes PE, Morris R, Avaniss-Aghajani E, Soriano T, Meraz M, et al. (2004) Topical tacrolimus therapy for vitiligo: therapeutic responses and skin messenger RNA expression of proinflammatory cytokines. J Am Acad Dermatol 51(1): 52-61.

15. Lerner AB (1959) Vitiligo. J Invest Dermatol 32: 285$310 . .1$

16. Mattoo SK, Handa S, Kaur I, Gupta N, Malhotra R (2002) Psychiatric morbidity in vitiligo: prevalence and correlates in India. J Eur Acad Dermatol Venereol 16(6): 573-578.

17. Dave S, Thappa DM, DSouza M (2002) Clinical predictors of outcome in vitiligo. Indian J Dermatol Venereol Leprol 68(6): 323-325.
18. Radtke MA, Schafer I, Gajur A, Langenbruch A, Augustin M (2009) Willingness-to-pay and quality of life in patients with vitiligo. Br J Dermatol 161(1): 134-139.

19. Borimnejad L, Yekta ZP, Nasrabadi AN, Firooz A (2006) Quality of life with vitiligo: Comparision of male and female muslim patients in Iran. Gender Medicine 3(2): 124-128.

20. Boissy RE (2000) The intrinsic (genetic) theory for the causes of vitiligo. In: Hann SK, Nordlund JJ (Eds.), Vitiligo. Oxford: Blackwell Science, pp:123-126.

21. Behl PN, Agarwal A, Srivastava G (1999) Etiopathogenesis of vitiligo: Are we dealing with an environmental disorder?. Ind J Dermatol Venereol Leprol 65(4): 161-167.

22. Martis J, Bhat R, Nandakishore B, Shetty JN (2002) A clinical study of vitiligo. Ind J Dermatol Venereol Leprol 68(2): 92-93.

23. Gopal K, Rama Rao GR, Kumar YH, Appa Rao MV, Vasudev P, et al. (2007) Vitiligo: A part of a systemic autoimmune process. Indian J Dermatol Venereol Leprol 73(3): 162-165. 